\title{
Conceptual design and aerodynamic evaluation of hypersonic airplane with double flanking air inlets
}

\author{
CUI Kai ${ }^{*}$, HU ShouChao ${ }^{1}$, LI GuangLi ${ }^{1}$, QU ZhiPeng ${ }^{1}$ \& SITU Ming ${ }^{2}$ \\ ${ }^{1}$ State Key Laboratory of High Temperature Gas Dynamics, Institute of Mechanics, Chinese Academy of Sciences, Beijing 100190, China; \\ ${ }^{2}$ The 31th Research Institute of CASIC, Beijing 100074, China
}

Received May 2, 2013; accepted June 18, 2013; published online July 2, 2013

\begin{abstract}
To aim at design requirements of high lift-to-drag ratio as well as high volumetric efficiency of next generation hypersonic airplanes, a body-wing-blending configuration with double flanking air inlets layout is presented. Moreover, a novel forebody design methodology which by rotating and assembling two waverider-based surfaces is firstly introduced in this paper. Some typical configurations are designed and their aerodynamic performances are evaluated by computational fluid dynamics. The results for forebodies analysis show that large volumetric efficiency, high lift-to-drag ratio, and uniformly distributed flowfield at the inlet cross section can be assured simultaneously. Furthermore, results of numerical simulation of four integrated configurations with various leading edge shapes, including three power-law curves and a cosine curve clearly show the advantage of high lift-to-drag ratio. Besides, the high pressure generated by the side wall of the airframe can be partly captured by the reasonably designed wings in the condition of small flight attack angle. Then the order of lift-to-drag ratio of four configurations at 0 degree flight attack angle is completely different from the condition of 4-degree flight attack angle. This result demonstrates that the curve shape of the leading edge is very important for the lift-to-drag ratio of the aircraft, and it should be further optimized under the cruising attack angle in future work.
\end{abstract}

hypersonic, flanking air inlet, waverider, computational fluid dynamics(CFD)

Citation: Cui K, Hu S C, Li G L, et al. Conceptual design and aerodynamic evaluation of hypersonic airplane with double flanking air inlets. Sci China Tech Sci, 2013, 56: 1980-1988, doi: 10.1007/s11431-013-5288-0

Air-breathing hypersonic vehicles has been much concerned by United States and other developed countries since the mid-20th century, and a series of research projects has been proposed since 1980s [1-3]. The completely integrated design of the airframe and propulsion system is generally adopted for the air-breathing hypersonic vehicles, however, as both the aerodynamic performance for the airframe and the engine intake/exhaust requirements shall be taken into account simultaneously, the design difficulty increased dramatically [1, 4-6]. As far as we know, the current aerodynamic design for hypersonic vehicles is mainly for the demonstration vehicles which focused on minimizing re-

*Corresponding author (email: kcui@imech.ac.cn) sistance and the optimal matching between airframe and engine, and the forebody and engine inlet integrated design is the key issues for the configuration design [7, 8].

The current air-breathing hypersonic vehicles can be mainly divided into two categories according to the different inlet layouts, i.e. with nose inlet and with ventral inlet. The hypersonic vehicle with nose inlet layout, such as the U.S. HyFly hypersonic demonstration vehicle [9], can efficiently achieve uniformly distributed airflow with high total pressure recovery coefficient for the engine by decreasing the interference of airframe to the maximum extent.. Moreover, the popular internal waverider inlet [7, 10-13] is also suited to the nose inlet layout [14]. The ventral inlet layout is the most commonly used layout for hypersonic vehicles, 
the U.S. X-43 and X-51 etc. demonstration hypersonic vehicles are all designed with ventral inlets $[1,4,5,7,8,15$, 16]. It is characterized with engine mounted on the abdomen, and the forebody is designed as a waverider or lifting-body which not only provides high-quality airflow for the engine inlet but also generate great lift force to improve the lift-to-drag ratio and pitching-balance performances of the vehicle [17-21].

With the progress of scramjet research, various airbreathing hypersonic vehicles are bound to gradually enter the practical stage. As the air-breathing hypersonic vehicle can be considered as a development of modern high-speed airplanes with the extended flight speed and flight altitudes, the existing design ideas/experience of high speed airplanes should be retained or referred to some typical high speed airplanes, such as the U.S. F-22 and F-35, are designed with flanking inlet, and the inlets are designed under the principle of shock-compression. F-22 is designed with caret inlet $[22,23]$ which is based on the waverider theory, and the airflow in the inlet is compressed by oblique shock wave. The BUMP inlet $[24,25]$ which is adopted by F-35, etc. is also designed under the waverider theory. By using a three-dimensional drum, it not only blows away the boundary layer, but also compresses the inlet airflow and provides high total pressure recovery coefficient flow for the engine. Obviously, with the flight Mach number of airplanes increasing, shock-compression based inlets, such as the waverider configuration and others, would become a trend for the further high-speed airplane. The Hypersonic Cruise Vehicle (HCV) proposed by the U.S. FALCON research program also adopts flanking inlet layout and internal waverider inlet $[26,27]$. But there are few published literatures about the $\mathrm{HCV}$, and its design philosophy remains to be in-depth study.

In view of the above-mentioned problems, the main objective of the present paper is to develop a conceptual design of air-breathing hypersonic airplane. By drawing on the merits of the existing airplane configuration design philosophy, a novel forebody design methodology which by rotating and assembling two waverider-based surfaces is firstly introduced in this paper, and a body-wing-blending configuration with double flanking air inlets layout is also presented. On this basis, a conceptual hypersonic airplane powered by double symmetric scramjet is proposed. Since numerical simulation has become a powerful tool of aerodynamic performance analysis [27-31], some typical configurations of forebodies and the whole airplanes with different wing leading edges are evaluated by CFD. The results for forebodies analysis show that large air mass flow, high lift-to-drag ratio, and uniformly distributed flowfield at the inlet cross section can be assured simultaneously. The results of the whole airplanes analysis show that high lift-to-drag ratio depends on the shape of the wing leading edge to a large extent.

\section{Configuration design ideas and features}

\subsection{Basic design ideas}

The paper focuses on the aerodynamic shape design of both forebody and the whole airframe. The specific design ideas are as follows: 1) The high-speed airplane design philosophy is taken as a reference, and the flanking inlet layout is chosen so as to ensure the satisfactory lift/drag and volume performance of the hypersonic airplane. The forebody/inlet integration design philosophy is also adopted to compress the engine inlet airflow by shock compression and to reduce the resistance to some extent. 2) The airframe is designed as body-wing-blending configuration so as to reduce the resistance caused by the interference between components and to relieve the safety issues caused by shock interaction. Furthermore, this configuration should have sufficient lift area to maintain the lift/weight balance.

Except the two aspects discussed above, some other design issues, such as the detail design of inlet, inner flow channel, jet nozzle and control planes, are not involved in this study. To facilitate the subsequent optimization, the configuration is parametrically designed by about 35 design parameters (which include the size parameters such as length, wingspan, section height of the body, section height of the wing, etc. and the line control parameters, such as the wing leading/trailing edge, etc.), and a Fortran-based configuration design code is developed which is independent of any other CAD design platform. Figure 1 shows a design example generated by this code, and it mainly contains three parts: forebody, wing-body and internal flow path. The basic design ideas and configuration features will be discussed below.

\subsection{Forebody design}

The primary consideration for the forebody design is its integration with the engine inlet, and we also hope that it shall have good performance in lift/drag and volume effi-

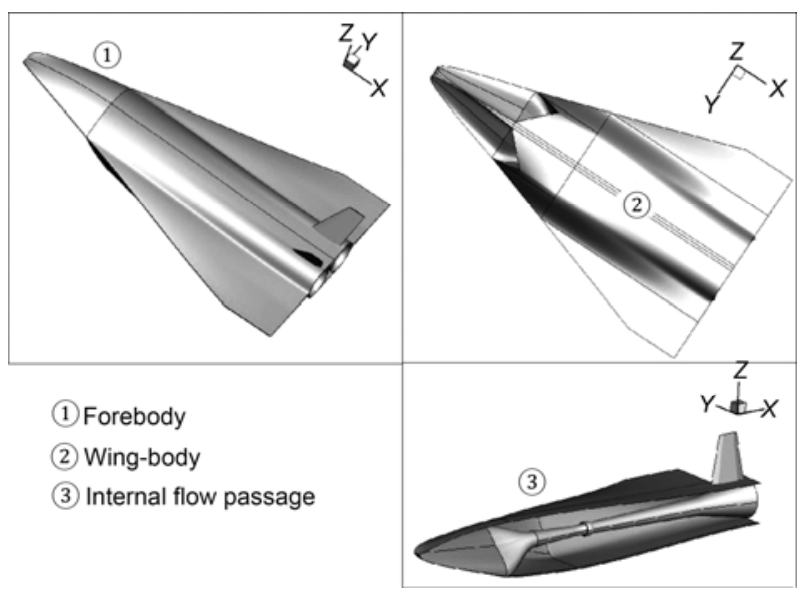

Figure 1 Design example of hypersonic airplanes. 
ciency. Accordingly, a novel forebody design methodology characterized by rotating and assembling two waveriderbased surfaces is proposed in this paper, as it shows in Figure 2.

With this design methodology, two waverider-based surfaces play the role of pre-compression surface for each engine, respectively, and the specific design ideas are detailed below. The basic compression surface which bases on waverider design philosophy would be obtained at first. Then, the two (left and right) surfaces rotate with angle of $\omega$, and are connected together by straight lines or curves. Finally, the rotating and assembling would match with the engine inlet. As it shows in Figure 2, three design parameters are used for this design, i.e. the rotating angle $\omega$, the minimum distance between the two basic compression surfaces $H_{2}$ and the height of the upper surface $H_{1} . \omega$ and $H_{2}$ can be adjusted to match the vertical height and horizontal spacing of the two engines, thus ensuring the internal airflow flowing straight through (without turning upward or right/left) and reducing the loss of total pressure accordingly. $H_{1}$ can be used to modify the volume of the forebody, greater $H_{1}$ means larger volume, but it always means greater resistance. The hypersonic airplane is designed with flanking inlet layout naturally and certain advantages of the existing highspeed airplane are retained by adopting this forebody configuration. However, its waverider nature is weakened because of the effect of the blunt leading edge and the connecting surface between the two basic compression surfaces, and this will be discussed in Section 2 .

\subsection{Body-wing-blending airframe design}

The airframe is designed as body-wing-blending configuration. To reduce the resistance, the whole configuration is designed with smooth surface and the stitching area between different parts is kept to be one order smooth at least. Large wing sweepback angle is also adopted to reduce the wave drag. The vertical position of the wing leading and trailing edge is chosen to be the position of forebody outer
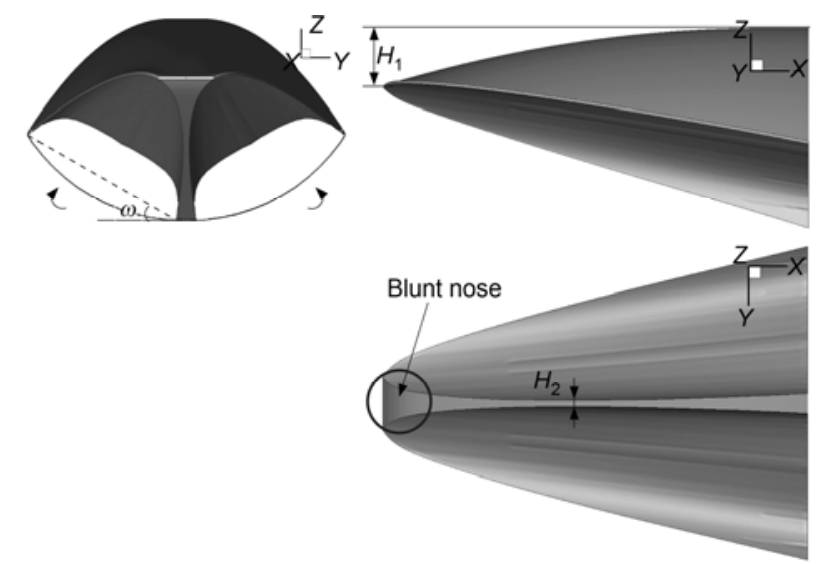

Figure 2 Design of airplane forebody by rotating and assembling two waveriders. edge and the engine axis vertical position respectively. The airframe is assembled with nonzero incidence angle (nonzero attack angle) due to the difference between the leading and trailing edge vertical positions, as a result, the airplane shows larger lift-to-drag ratio even it flies with small attack angle. In addition, the internal volume can be enlarged by raising the upper surface.

\section{Effect of design parameters on forebody}

As it is mentioned in Section 1.2, the lift/drag performance and the uniformity of the inlet airflow would be affected by the detached shock wave which was mainly caused by the connection surface between the two basic compression surfaces. This section gives some specific forebodies with different $\omega$ and $H_{2}$ to analyze the effect of $\omega$ and $H_{2}$ on the aerodynamic performances of the forebody. Two conederived waveriders with conic leading edge are used for the basic compression surface. The thickness of the leading edge and the height of the upper surface $H_{1}$ are fixed to be 10 and $200 \mathrm{~mm}$, respectively. The flight condition is set to be flight Mach number 6 and flight altitude $25 \mathrm{~km}$. The aerodynamic performances are evaluated by CFD with laminar flow model.

Figures 3 and 4 show the pressure and Mach number contours comparison between forebodies with different rotating angles $\omega$. When $\omega$ is small, the connection surface of the forebody presents smaller width near the trail and greater width near the nose. The blunter nose-tip means a stronger detached shock wave which interferes with the downstream flowfield. As $\omega$ increases, the width near the trail increases while the width near the nose decreases, the detached shock wave becomes weaker and the interference with the downstream flowfield is weakened accordingly. As it is shown in Figures 3 and 4 , when $\omega$ is about $45^{\circ}$, the pressure and Mach number distribution at the inlet section of the inlet are nearly uniform. Obviously, greater $\omega$ helps weaken the detached shock wave in front of the nose-tip and weaken the interference with the downstream flowfield accordingly.

Figure 5 presents the variation of lift coefficient, drag coefficient and lift-to-drag ratio with different $\omega$. As $\omega$ increases, the effective lifting area of the basic compression surfaces decreases and the shock wave in front of the nose-tip is weakened, as a result, both the lift and drag coefficients decrease. However, as the area of connection surface (with high pressure on the surface) increases, the lift coefficient and lift-to-drag ratio increase for $\omega \neq 60^{\circ}$ case compared to that of $\omega=60^{\circ}$ case.

Figure 6 shows the pressure contours comparison between forebodies with different $H_{2}$ (where $\omega$ is fixed to be $30^{\circ}$ ). As the figure shows, the nose-tip of the forebodies is changed little while $H_{2}$ varies within a small range (10-25 


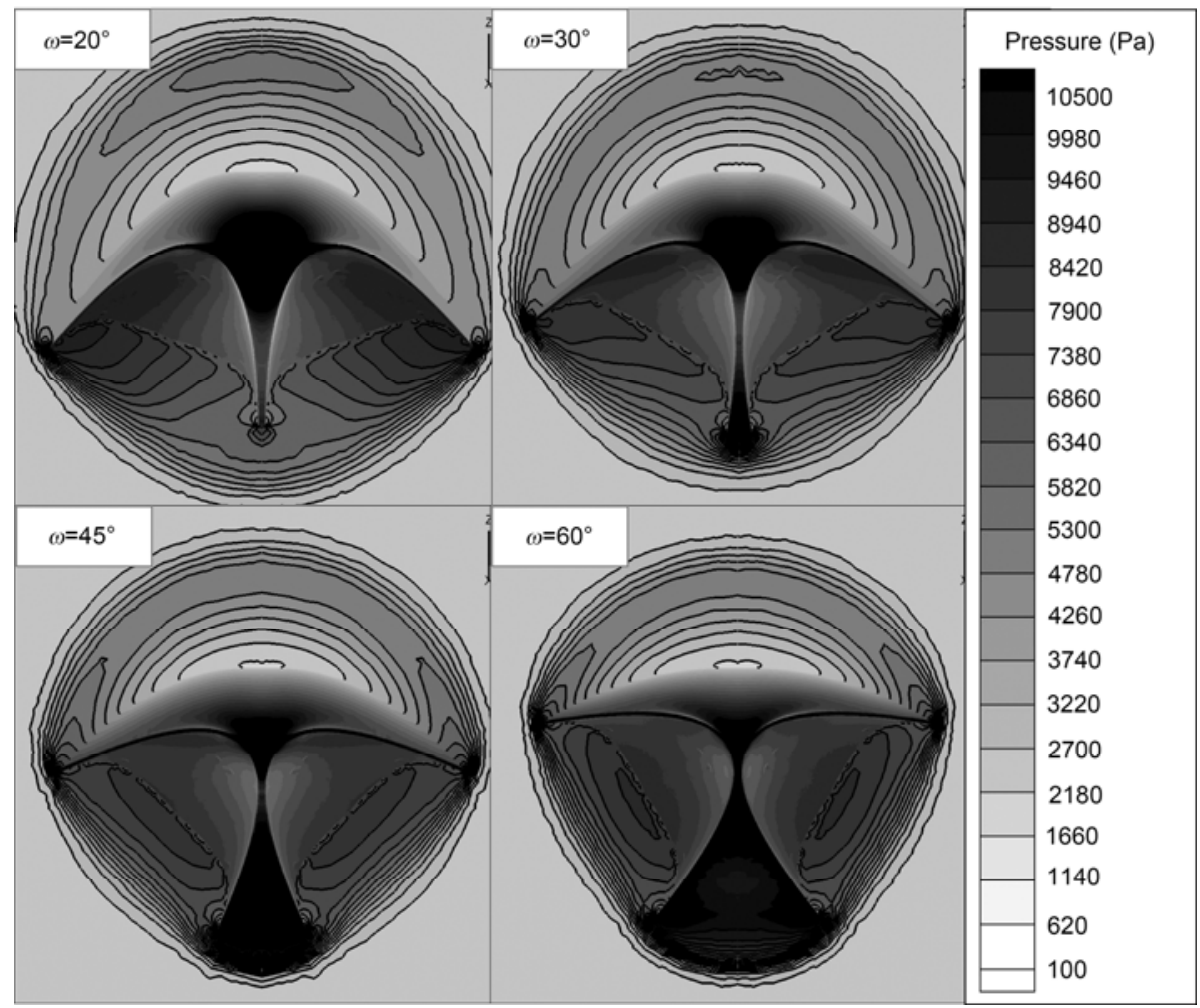

Figure 3 Comparison of wall and cross section pressure contours in the forebody for different $\omega$ values $\left(H_{2}=20 \mathrm{~mm}\right)$.

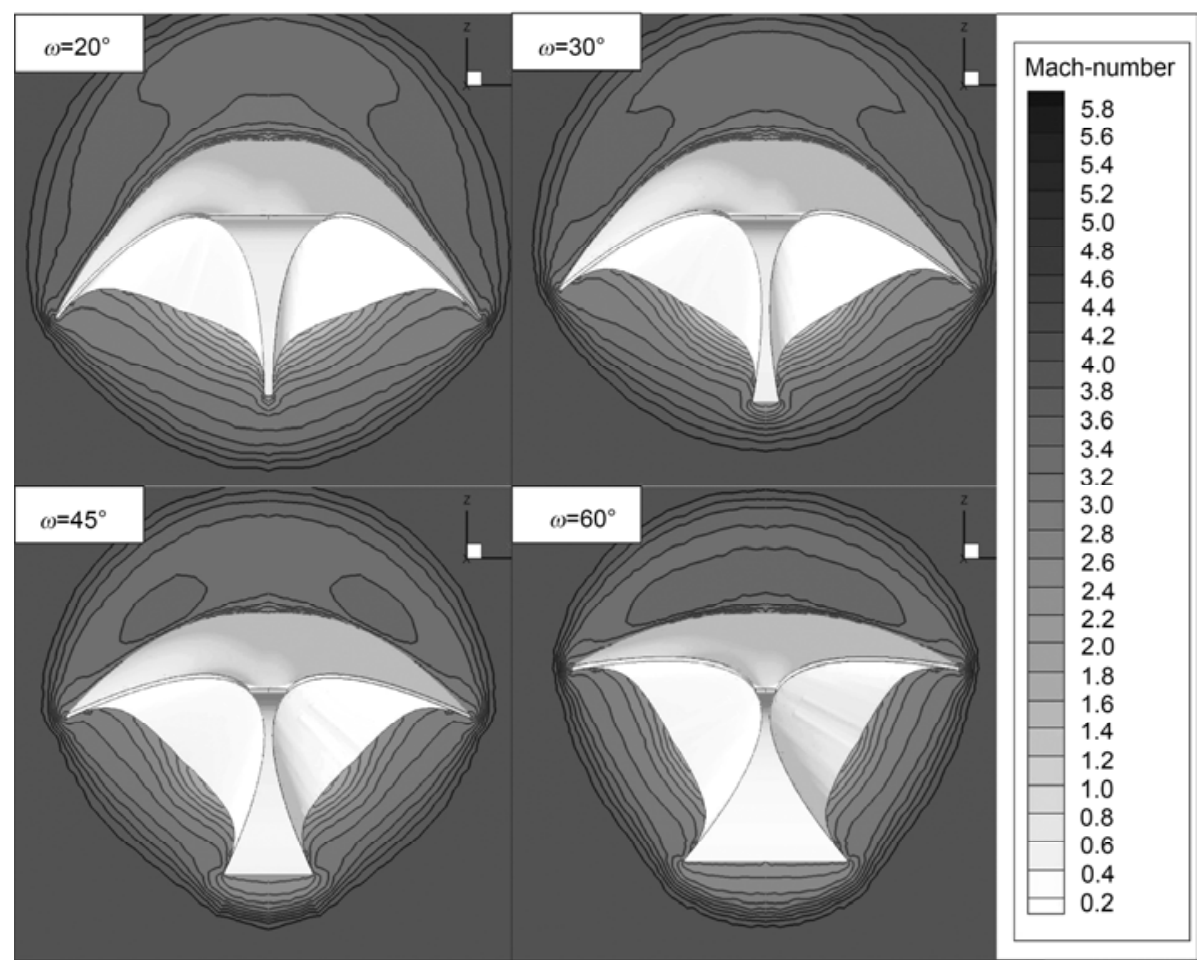

Figure 4 Comparison of Mach number contours on the cross section of the inlet for different $\omega$ values $\left(H_{2}=20 \mathrm{~mm}\right)$.

$\mathrm{mm}$ ), and the pressure contours at the section of the inlet is changed little accordingly. As $H_{2}$ increases, the area of the connection surface increases, and the lift coefficient, drag coefficient and lift-to-drag ratio increase slightly (Table 1) as a result.

The results suggest that the forebody designed by rotat- 


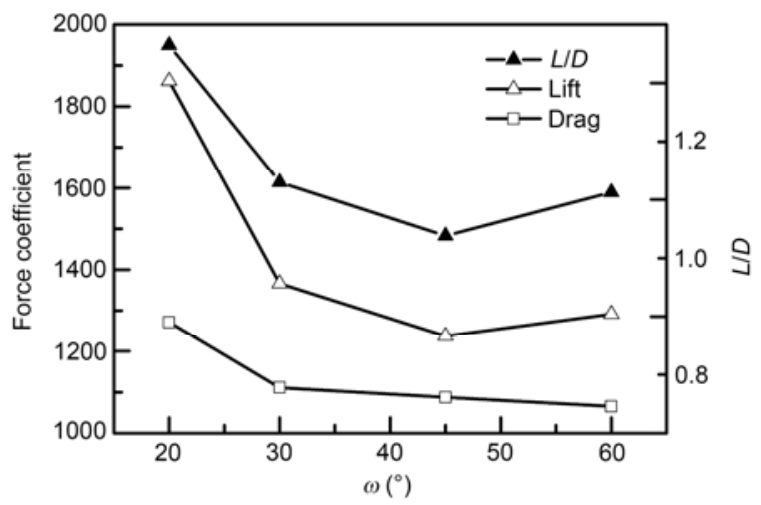

Figure 5 Variation of lift/drag coefficients and the $L / D$ of the forebody with different $\omega$ values.

ing and assembling two waverider-based surfaces is able to provide uniform airflow for the engine inlet while reasonable design parameters $\omega$ and $H_{2}$ are chosen. And it also shows good lift/drag performances. In addition, the results show that $\omega$ is more important when the uniformity of the inlet flowfield and lift/drag performance of the forebody are concerned.

\section{Evaluation of the aerodynamic performance of the airplane}

The whole configuration (with $\omega=30^{\circ}, H_{1}=200 \mathrm{~mm}, H_{2}=15$ $\mathrm{mm}$ ) is given based on the forebody analysis, and its aero- dynamic performance is also evaluated by numerical simulation. For the airplane designed by fully parametric design methodology, four configurations with different wing leading edges are obtained conveniently. Figure 7 illustrates the top view comparison of the four different airplanes, the top projected shape of the wing leading edge is cosine-curve $\left(\mathrm{CFG}_{-} \mathrm{C}\right)$ and power-law-curve with power of $0.8\left(\mathrm{CFG}_{-}\right.$ P0.8), 1.0 (CFG_P1.0, that is straight line), 1.2 (CFG_P1.2) respectively. The thickness of the leading edge is set to be $10 \mathrm{~mm}$. Table 2 compares the top project areas of the forebodies, wing-bodies and whole configurations.

The flight condition is also set to be flight Mach number 6 and flight altitude of $25 \mathrm{~km}$. The internal flow path (as shows in Figure 1) and rear control plan are not considered, and the boundary condition of the forebody outlet is set to be pressure outlet accordingly. The unstructured tetrahedral mesh with about eight million volumes is used and the laminar flow model is adopted for the simulation.

\subsection{Aerodynamic performance analysis for different flight attack angles}

The aerodynamic performance for different flight attack angles $\left(-2^{\circ}\right.$ to $\left.10^{\circ}\right)$ is analyzed based on CFG_P1.2 configuration as it has the maximum top projected area. As Figure 8 presents, the lift coefficient increases linearly and the drag coefficient increases quadratically as the attack angle increases, and the wing-body provides most of the lift force, especially for large attack angle.

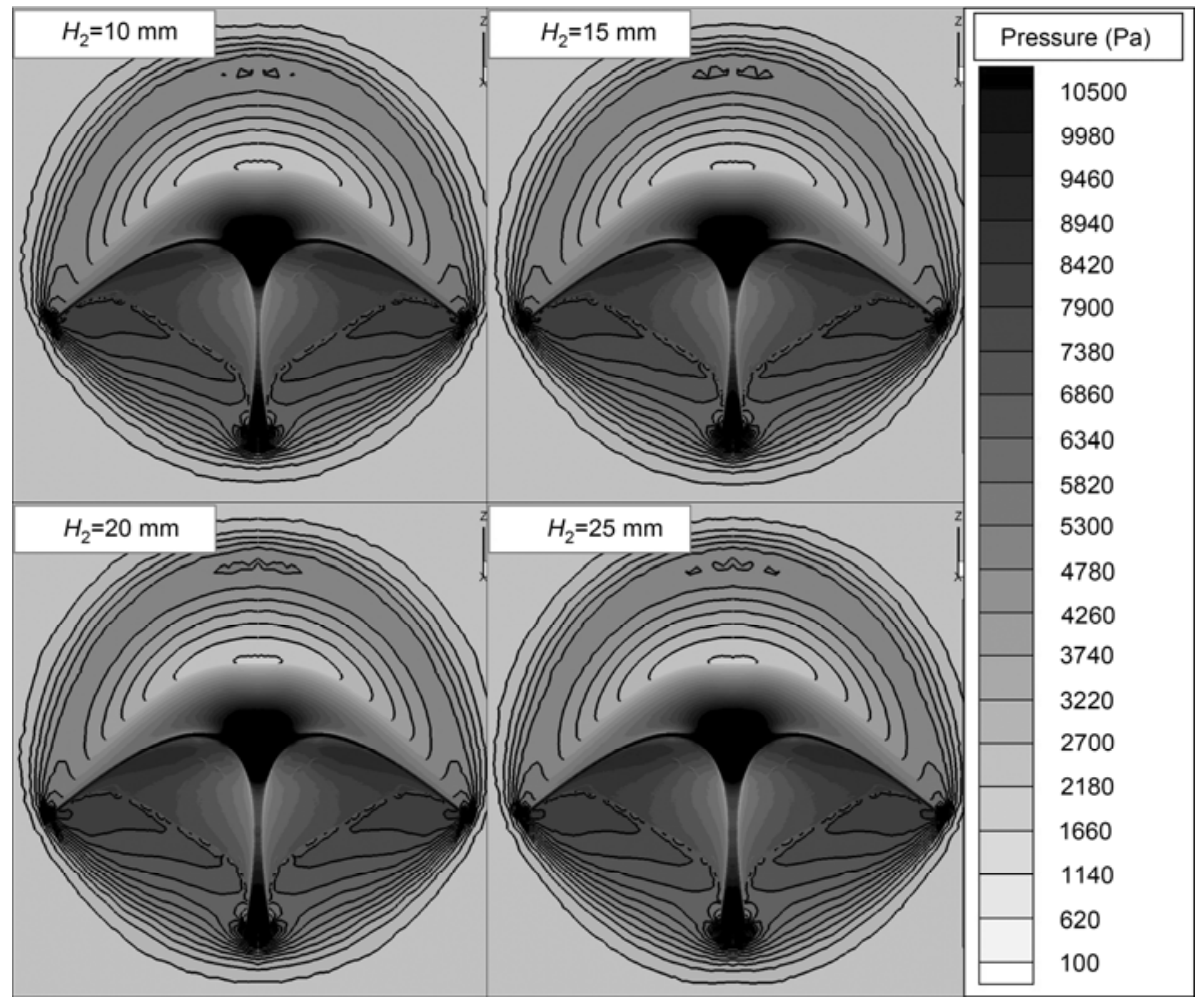

Figure 6 Comparison of the pressure contours on the wall and the outlet cross section of the forebody for different $H_{2}$ values. 
Table 1 Variation of lift/drag coefficients and the $L / D$ of the forebody versus $\mathrm{H}_{2}$

\begin{tabular}{cccc}
\hline$H_{2}(\mathrm{~mm})$ & $C_{1}$ & $C_{\mathrm{d}}$ & $L / D$ \\
\hline 10 & 0.048571 & 0.039757 & 1.22 \\
15 & 0.049675 & 0.040466 & 1.23 \\
20 & 0.050907 & 0.041398 & 1.23 \\
25 & 0.052031 & 0.041981 & 1.24 \\
\hline
\end{tabular}

Table 2 Planform projected area of components and integrated configurations

\begin{tabular}{cccc}
\hline Configuration & Forebody $\left(\mathrm{m}^{2}\right)$ & Wing-body $\left(\mathrm{m}^{2}\right)$ & Total $\left(\mathrm{m}^{2}\right)$ \\
\hline CFG_C & 0.47 & 4.28 & 4.75 \\
CFG_P0.8 & 0.47 & 4.11 & 4.58 \\
CFG_P1.0 & 0.47 & 4.28 & 4.75 \\
CFG_P1.2 & 0.47 & 4.42 & 4.89 \\
\hline
\end{tabular}

Figure 9 shows the lift-to-drag ratio of the main components and whole airplane, and the mass flow of the inlet for different attack angles. As the figure shows, the forebody reaches the maximum lift-to-drag ratio 2.57 at attack angle of $6^{\circ}$, whereas, the wing-body and whole airplane reach the maximum lift-to-drag ratio $(5.45,4.34$ respectively) at the attack angle of $4^{\circ}$. What is more, the mass flow of the inlet increases linearly with the increase of the attack angle.

\subsection{Effect of wing-leading-edge shape on aerodynamic performance of the airplane}

The results of Section 3.1 suggest that the maximum lift-torag ratio of the whole airplane may be obtained at $4^{\circ}$ attack angle, so the aerodynamic performance comparison for the four configurations is carried out at $4^{\circ}$ attack angle. The

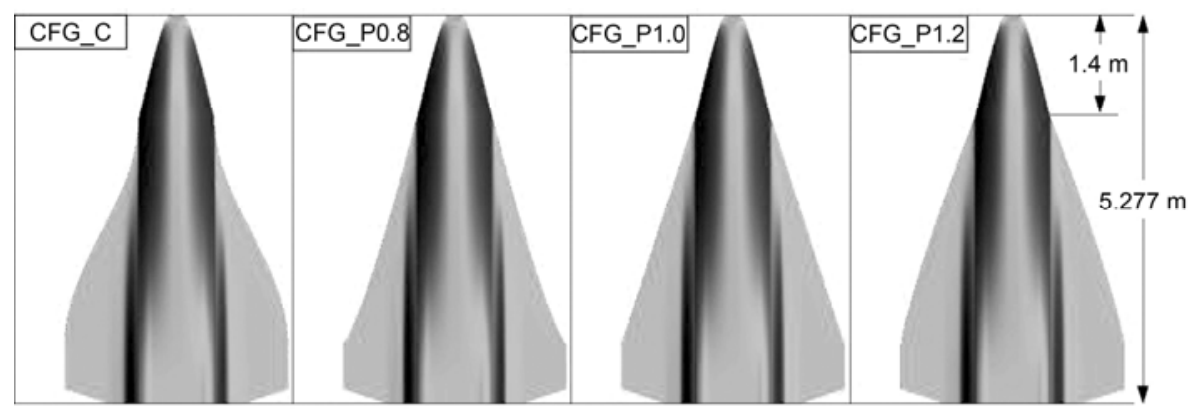

Figure 7 Planforms of four integrated configurations.
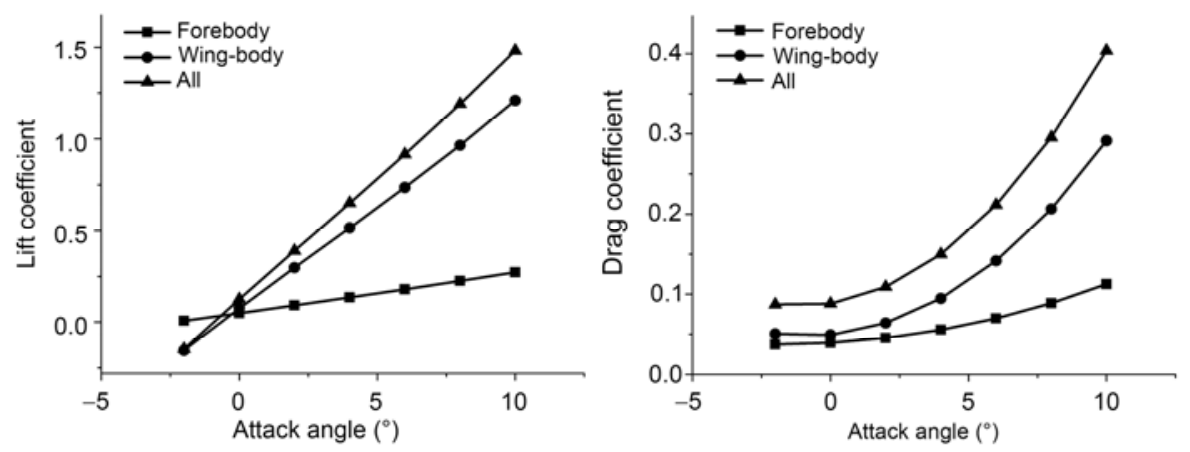

Figure 8 Lift and drag coefficients of CFG_P1.2 for different attack angles.
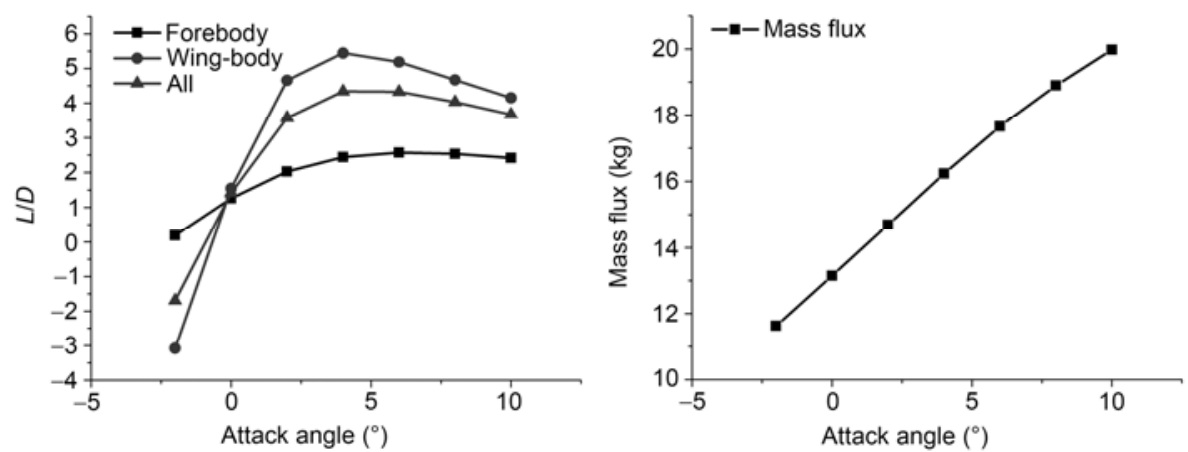

Figure 9 The $L / D$ and air flux of CFG_P1.2 for different attack angles. 
results are shown in Table 3 , and the performances at $0^{\circ}$ attack angle are also given for comparison. The results show that the lift-to-drag ratios are all greater than 1 even at $0^{\circ}$ attack angle, which benefits from the rational forebody configuration and the nonzero attack angle of the wing when it is assembled. Meanwhile, the maximum lift-to-drag ratio difference for the four configurations reaches about $12 \%$ (between CFG_P1.2 and CFG_P0.8) and 8\% (between CFG_C and CFG_P1.2) at $0^{\circ}$ and $4^{\circ}$ attack angles, respectively, which means that the shape of the leading edge is quite important for the aerodynamic performances of the airplane. The lift-to-drag ratios are all greater than 4 and the maximum value reaches 4.68 for $\mathrm{CFG}_{-} \mathrm{C}$ at $4^{\circ}$ attack angle, provided the internal flow passage resistance is not considered. In addition, the numerical results also show that the configurations have different sorts of lift-to-drag ratio when they are flying at $0^{\circ}$ and $4^{\circ}$ attack angles.

For further analysis, the lift/drag coefficients of the forebody and wing-body are studied separately. As it is shown in Figure 10, the lift and drag coefficient of the forebody shows little change between the four airplanes provided they are designed to have the same forebody configuration. At $0^{\circ}$ attack angle, about $50 \%$ of the lift and drag is generated by the forebody though its geometric size is much smaller than that of the wing-body. It means that the aerodynamic performance of the forebody is quite important for the airplane, especially at $0^{\circ}$ or small attack angle, and it also suggests that the forebody configuration with double waverider-based surfaces retains the high lift-to-drag ratio character of the waverider. In addition, Figure 10 shows that the lift coefficient of the wing-body is proportional to its area. However, although CFG_C and CFG_P1.0 have the same wing-body area, the CFG_C shows smaller drag and lift but higher lift-to-drag ratio (greater than about $1.5 \%$ )

Table 3 Comparison of lift and drag coefficients and $L / D$ between four configurations

\begin{tabular}{|c|c|c|c|c|c|c|}
\hline \multirow{2}{*}{ Configuration } & \multicolumn{2}{|c|}{$C_{1}$} & \multicolumn{2}{|c|}{$C_{\mathrm{d}}$} & \multicolumn{2}{|c|}{$L / D$} \\
\hline & $\alpha=0^{\circ}$ & $\alpha=4^{\circ}$ & $\alpha=0^{\circ}$ & $\alpha=4^{\circ}$ & $\alpha=0^{\circ}$ & $\alpha=4^{\circ}$ \\
\hline CFG_C & 0.1076 & 0.6297 & 0.07814 & 0.1347 & 1.38 & 4.68 \\
\hline CFG_P0.8 & 0.0945 & 0.5915 & 0.07476 & 0.1292 & 1.27 & 4.58 \\
\hline CFG_P1.0 & 0.1099 & 0.6235 & 0.08089 & 0.1391 & 1.36 & 4.48 \\
\hline CFG_P1.2 & 0.1249 & 0.6509 & 0.08814 & 0.1501 & 1.42 & 4.34 \\
\hline
\end{tabular}

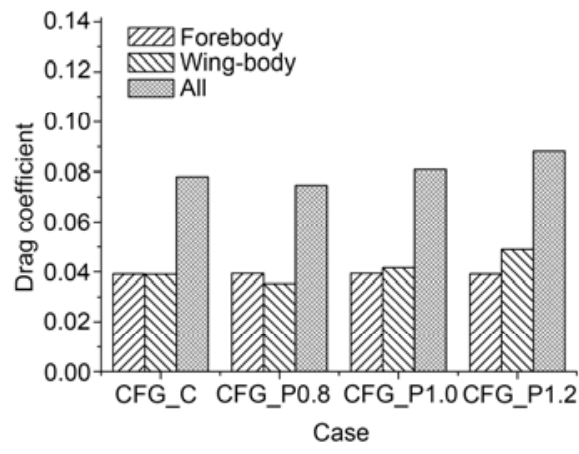

because of the difference in the shape of wing leading edge.

Figure 11 shows the lift and drag coefficient comparison between the four airplanes. The performances are taken at $0^{\circ}$ attack angle as a basis of comparison, the wing-body holds a large proportion (about $80 \%$ ) of the total lift though the sort of lift and drag coefficient is unchanged. It is obvious that CFG_P1.2 has greater lift and drag coefficient than the others, but it shows the smallest lift-to-drag ratio, exactly opposite to the performances at $0^{\circ}$ attack angle. As Table 3 and Figure 11 show, CFG_C and CFG_P1.0 have the same top projected area and the same frontal area when flying at $4^{\circ}$ attack angle, but CFG_C experiences greater lift and smaller drag, and its lift-to-drag ratio is increased by about $4.5 \%$ accordingly.

Figure 12 shows the pressure contours comparison between four different configurations. There are two high pressure areas caused by the swell on both sides of the front part of the body. The high pressure leads to increase in both lift and drag. As shown in Figure 12, the high pressure area of the CFG_C is much smaller because the cosine-curved wing leading edge has greater sweepback angle at the front part of the wing-body, and the drag coefficient reduces accordingly. What is more, the wing of CFG_C can efficiently capture the high pressure caused by side compression, and the lift coefficient increases accordingly. Therefore, CFG_C shows smaller drag, greater lift and higher lift-to-drag ratio at $4^{\circ}$ attack angle. It implies that the lift-to-drag ratio would be further improved by optimizing the shape of the wing leading edge at small attack angle.

\section{Conclusions and discussions}

The main objective of the paper is to develop a conceptual design of air-breathing hypersonic airplanes. A novel forebody design methodology, which is characterized by rotating and assembling two waverider-based surfaces, is firstly introduced in this paper, thereby a body-wing-blending configuration with double flanking air inlets layout is presented. Based on a fully parametric design of the airplane, typical forebodies and airplane configurations are chosen for the analysis of their aerodynamic performances. The flowfield

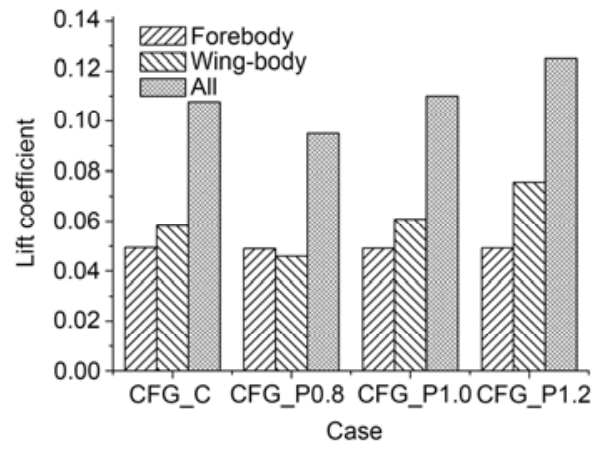

Figure 10 Lift and drag coefficients of airplanes and their components at $0^{\circ}$ attack angle. 

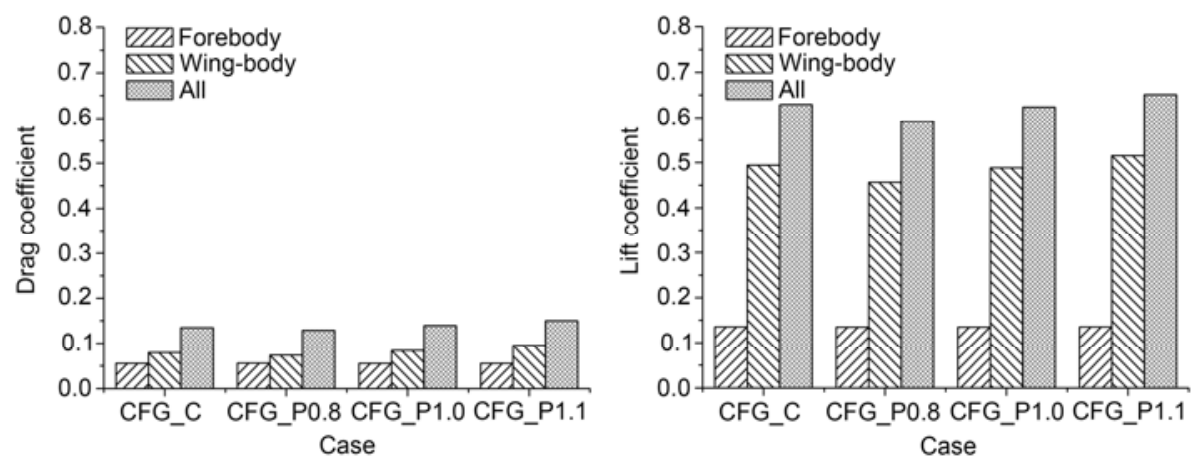

Figure 11 Lift and drag coefficients of airplanes and their components at $4^{\circ}$ attack angle.

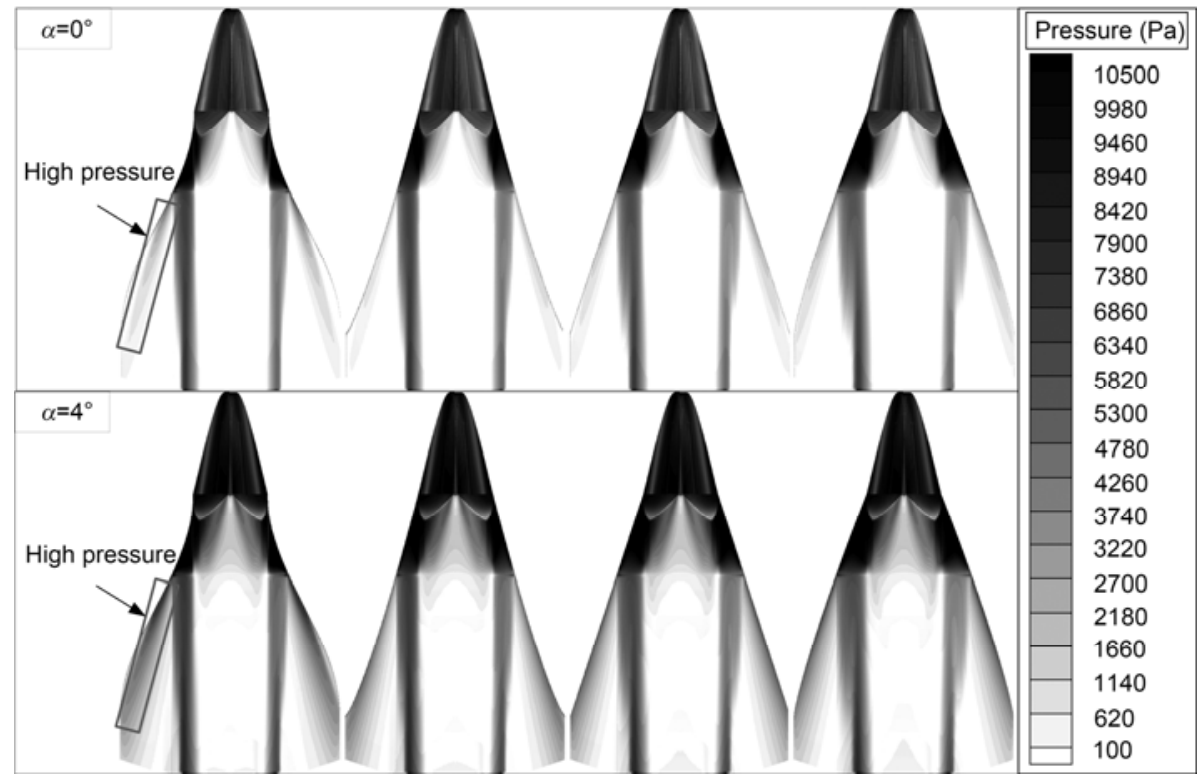

Figure 12 Pressure contours on the lower surface of four configurations.

is simulated by CFD and the flight condition is set to be flight Mach number 6 with flight altitude of $25 \mathrm{~km}$. The preliminary results show that the forebody configuration with double waverider-based surfaces retains the advantages of the waverider. The compression surface designed by waverider philosophy not only compresses the airflow satisfactorily, but also provides high lift for the forebody.

However, the results also show that the aerodynamic performance of the compression surfaces and the airflow uniformity at the inlet cross section are interfered by the detached shock wave resulting from the blunt nose. The detached shock wave and the corresponding interference can be weakened if the connection surface spacing near the nose-tip is reduced. As only the conic leading edge of the basic waverider surface is used in this study, the detached shock wave and the corresponding interference would be further weakened if the leading edge of the basic waverider surface is designed to take some other curves (such as the straight line). Besides, the numerical evaluation of the whole airplane shows that, the forebody holds about $50 \%$
(20\%) of the total drag (lift) when it flies at $0^{\circ}$ and $4^{\circ}$ attack angles, respectively, though its geometric size is much smaller than that of the wing-body (it holds only $10 \%$ of the total top projected area). It suggests that both the airflow compression and lift/drag performance should be of much concern in the design of forebody. The comparison between four configurations with different wing leading edges shows that the shape of the wing leading edge is quite important for the lift and drag performance. The CFG_C configuration with cosine-curved wing leading edge has smaller drag, greater lift and higher lift-to-drag ratio, as it benefits from the reduction of wave drag and the wing's capability of capturing the high pressure caused by side compression.

Further work for the design of the engine inlet and the optimization design of wing leading edge will be carried out based on this study. As the forebody with double waveriderbased surfaces retains advantages of the waverider, such as high mass flow, high lift-to-drag ratio, etc., the existing ventral inlet design experience can be useful for the inlet design. In addition, the optimization of the wing leading 
edge shall focus on the cruise flight condition (taking the present study as an example, the configurations have different sorts of lift-to-drag ratio at $0^{\circ}$ and at $4^{\circ}$ attack angles), and the target shall be the reduction of wave drag and efficient capture of the high pressure caused by side compression. Eventually, as this work is only a conceptual design, analysis and solutions of the latent issues will also be performed in subsequent studies.

This work was supported by the National Natural Science Foundation of China (Grant No. 90916013) and the guidance and help from Academician Li Tian and peer reviewers are gratefully acknowledged.

1 Cui E J. Research statutes, development trends and key technical problems of near space flying vehicles (in Chinese). Adv Mech, 2009, (6): 658-673

2 Le J L. Progress in air-breathing hypersonic technology (in Chinese). J Southwest Univ Sci Technol, 2011, 26(4): 1-9

3 Ye Y D. Study on aerodynamic characteristic and design of optimization for high speed near space vehicles (in Chinese). Adv Mech, 2009, (6): 683-694

4 Bertin J J, Cummings R M. Fifty years of hypersonics: where we've been, where we're going. Prog Aerosp Sci, 2003, 39(6): 511-536

5 Bakos R. Current hypersonic research in the USA. Adv Propul Technol High-Speed Aircr, 2008, 10: 1-26.

6 Huang W, Li S B, Liu J, et al. Investigation on high angle of attack characteristics of hypersonic space vehicle. Sci China Tech Sci, 2012, 55(5): 1437-1442

7 You Y C, Liang D W. Design concept of three-dimensional section controllable internal waverider hypersonic inlet. Sci China Tech Sci, 2009, 52(7): 2017-2028

8 Lewis M J. A hypersonic propulsion airframe integration overview. AIAA- 2003-4405, 2003

9 Zhang M Z, Zou Y. Development of American typical hypersonic flight vehicles and its enlightenment (in Chinese). J Rock Propul, 2012, 38(2): 1-8

10 Mölder S. Internal, axisymmetric, conical flow. AIAA J, 1967, 7(5): 1252-1255

11 Billig F S, Baurle R A, Tam C J. Design and analysis of streamline traced hypersonic inlets. AIAA-1999-4974, 1999

12 Sun B, Zhang K Y. Experimental investigation and numerical simulation of hypersonic Busemann inlet (in Chinese). J Propul Technol, 2006, 27(1): 58-61

13 Kothari A P, Tarpley C, McLaughlin T. Hypersonic vehicle design using inward turning flowfields. 32nd AIAA/SAE/ASME/ASEE Joint Propulsion Conference, AIAA, 1996
14 Kothari A P. Designs of and methodology for inward or outward, and partially inward or outward turning flow hypersonic air-breathing and rocket-based-combined-cycle vehicles. Patent Application Publication, US6164596 A, USA, 2000

15 Tan H J, Chen Z, Li G S. A new concept and preliminary study of variable hypersonic inlet with fixed geometry based on shockwave control. Sci China Tech Sci, 2007, 50(5): 644-657

16 Huang W, Li S B, Liu J, et al. Effect of cavity flame holder configuration on combustion flow field performance of integrated hypersonic vehicle. Sci China Tech Sci, 2010, 53(10): 2725-2733

17 Takashima N, Lewis M J. Engine-airframe integration on osculating cone waverider-based vehicle designs. AIAA-1995-2551, 1995

18 O'Neill M K L, Lewis M J. Optimized scramjet integration on a waverider. J Aircr, 1992, 29(6): 1114-1121

19 Cui K, Zhao D X, Yang G W. Waverider configurations derived from general conical flowfields. Acta Mech Sin, 2007, 23(3): 247-255

20 Cui K, Yang G W. The effect of conical flowfields on the performance of waveriders at Mach 6. Chin Sci Bull, 2007, 52(1): 57-64

21 Che J, Tang S, Bingnan K. Airframe/scramjet integrated design of hypersonic cruise vehicle. AIAA-2007-642, 2007

22 Townend $\mathrm{L}$ H. On hypersonic cruising aircraft which can have all leading edges swept. Part I, Design of air intakes. RAE Report TR 67046, 1967

23 Zhu Y, Li T. Overview of caret inlet researches (in Chinese). Aircr Design, 2003, (1): 1-6

24 Yang Y K. The research of bump inlet design and test (in Chinese). Acta Aerodyn Sin, 2007, 25(3): 336-338

25 Zhu Y, Li T. The study of BUMP intake design (in Chinese). Proceedings of the First National Symposium of Mechanics Problems in the Aerospace Field (Part 1), Chengdu, Sichuan, 2004

26 Elvin J D. Integrated inward turning inlets and nozzles for hypersonic air vehicles. European Patent Application EP1818257, 2007

27 Walker S H, Sherk J, Shell D. The DARPA/AF falcon program: the hypersonic technology vehicle\# 2(HTV-2) flight demonstration phase. AIAA-2008-2539, 2008

28 Tu G H, Deng X G, Mao M L. Validation of a RANS transition model using a high-order weighted compact nonlinear scheme. Sci China Phys Mech Astron, 2013, 56 (4): 805-811

29 Fan M, Cao W, Fang X J. Prediction of hypersonic boundary layer transition with variable specific heat on plane flow. Sci China Phys Mech Astron, 2011, 54(11): 2064-2070

30 Dong $\mathrm{M}$, Zhou $\mathrm{H}$. The effect of high temperature induced variation of specific heat on the hypersonic turbulent boundary layer and its computation. Sci China Phys Mech Astron, 2010, 53(11): 21032112

31 Wang L, Fu S. Modeling flow transition in a hypersonic boundary layer with Reynolds-averaged Navier-Stokes approach. Sci China Ser G-Phys Mech Astron, 2009, 52(5): 768-774 